\title{
Evaluation of Decolorization, Mineralization, and Toxicity Reduction of an Azo Dye C.I. Reactive Black 5 in a Countercurrent Bubble Column by Ozone
}

\author{
Hao-Jan Hsing ${ }^{1}$; Pen-Chi Chiang²; and E. E. Chang ${ }^{3}$
}

\begin{abstract}
A countercurrent and continuous-flow design bubble column reactor (BCR) was used to investigate variations in traditional parameters of water-containing Reactive Black 5 (RB5) under different gas/liquid flow rates. RB5 is a long-chain diazo dye with a high molecular weight that is widely applied in industry. The results revealed that the variations were functions of the flow rates of the liquid and/or gas and of operation column height. Pseudo-first-order or global-second-order reaction types were used to describe the variations, and the monitored parameters i.e., total organic carbon (TOC), sulfate, and nitrate. Not only did flow patterns affect the RB5 removal and the mineralization of derivatives, but column height might also have had an influence on ozone consumption. It was observed that the extent of decolorization and mineralization decreased as the sampling port height increased, indicating that the column height may reflect the retention time of ozone gas and the contacting time between ozone and RB5 in the BCR system. Biodegradability was enhanced by ozone treatment, although the effect was not proportional to the amount of ozone consumption. An experimental regression model was proposed to predict the variations in color $_{i} / \mathrm{color}_{0}, \mathrm{TOC}_{i} / \mathrm{TOC}_{0}$, and sulfate yield $\left(Y_{\mathrm{SO}_{4}^{2-}}\right)$ throughout this investigation.
\end{abstract}

DOI: $10.1061 /(\mathrm{ASCE}) 1090-025 \mathrm{X}(2006) 10: 1(10)$

CE Database subject headings: Dyes; Colors; Biodegradation; Toxicity; Ozonization; Water pollution.

\section{Introduction}

Water treatment by ozone has been widely used for decades, and its application in the field of wastewater treatment has been intensively studied in recent years. One of the most powerful oxidants $\left(E^{0}=2.07 \mathrm{~V}\right)$, ozone, is produced via electrical discharge into pure oxygen or oxygen-enriched gas (Chen et al. 2003) and is used in the treatment of water or wastewater for pollutant removal and disinfection. With this unique advantage, ozone is also a selective oxidant that will react with a compound containing unsaturated bonds more rapidly than with others.

Over $50 \%$ of commercial dyes used in the textile industry are azo dyes that contain unsaturated azo bonds $(\mathrm{N}=\mathrm{N})$, which have various azo bonds and chromophores to allow for customized color requirement and finishing purposes. Some azo dyes not only cause allergies, but also exhibit toxic and even mutagenic or carcinogenic properties (Pielesz et al. 2002); over 27 azo dyes have been removed from the market due to strict regulations (European

${ }^{1}$ Graduate Student, Graduate Institute of Environmental Engineering, National Taiwan Univ., 71 Chou-Shan Rd., Taipei, Taiwan 106, ROC. E-mail: d89541007@ntu.edu.tw

${ }^{2}$ Professor, Graduate Institute of Environmental Engineering, National Taiwan Univ., 71 Chou-Shan Rd., Taipei, Taiwan 106, ROC (corresponding author). E-mail: pcchiang@ntu.edu.tw

${ }^{3}$ Professor, Dept. of Medicine, Taipei Medicine Univ. $250 \mathrm{Wu}-\mathrm{Hsing}$ St., Taipei, Taiwan 106, ROC. E-mail: eechang@tmu.edu.tw

Note. Discussion open until June 1, 2006. Separate discussions must be submitted for individual papers. To extend the closing date by one month, a written request must be filed with the ASCE Managing Editor. The manuscript for this paper was submitted for review and possible publication on July 26, 2005; approved on July 26, 2005. This paper is part of the Practice Periodical of Hazardous, Toxic, and Radioactive Waste Management, Vol. 10, No. 1, January 1, 2006. CASCE, ISSN 1090-025X/2006/1-10-18/\$25.00.
Union 2003). Since dyestuff cannot be utilized in its entirety during dye bath processes, it is discharged along with rinse water containing high levels of dye residue that is difficult to remove by traditional treatment methods. Thus, the effluent water from secondary treatment plants still contain dye residues; the associated color is aesthetically displeasing, inducing major complaints from local communities. Further, the effluent-containing dye residue represents an increasing danger in aquatic life due to its toxicity and potentially carcinogenic nature.

Ozonation, as one of the promising advanced oxidation processes, has been used in treating colored water and has proven its ability to treat wastewater, especially that of the textile industry (Wu and Wang 2001; Adams and Gorg 2002). With the high oxidation capability, ozone has been successfully used in water and wastewater treatment in removing color, reducing the chemical oxygen demand (COD) and total organic carbon (TOC) of wastewater (Arslan and Balcioglu 2000; Sevimli and Sarikaya 2002; Wang et al. 2003). The bubble column reactor (BCR) has commonly been applied in water treatment by ozone contacting (Chiang et al. 1999; Hermanowicz et al. 1999) that offers advantages, such as no moving parts, high liquid-phase content for treatment, high mass transfer rate, low-energy input, and less required space (Deckwer and Schumpe 1993). The flow in the BCR may be co-current or counter current, depending on the liquid and gas flow directions. Based on the previous studies, the counter-current flow type of BCR has a high mass transfer efficiency compared to the co-current type (Zhou et al. 1994; Chen et al. 2002).

The target compound used in this study, Reactive Black 5 (RB5), is typical of the azo dyes widely used in the textile industry, and its degradation has been studied (Ince and Tezcanlí 2001) as well as its toxicity reduction (Wang et al. 2003) in a semibatch system. The objectives of this study are: (1) to investigate the effect of the ratio of gas and liquid on the degradation of RB5 in 


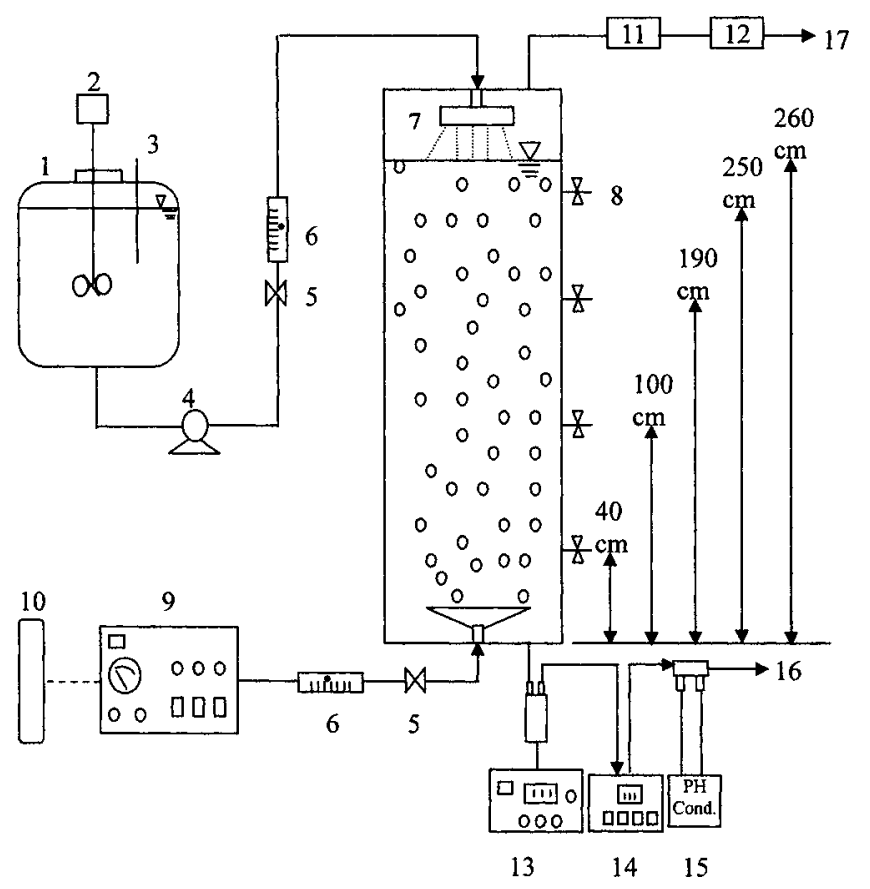

Fig. 1. The experimental apparatus sketch. Components: (1) storage tank; (2) stirrer; (3) thermostat and level alarm; (4) pumps; (5) flow control valve; (6) precision flow controller; (7) liquid sparger; (8) sampling ports; (9) ozone generator; (10) oxygen cylinder; (11) gaseous ozone detector; (12) ozone destroyer; (13) liquid ozone monitor; (14) photospectrometer; (15) $\mathrm{pH}$ and conductivity sensors; (16) draining; and (17) venting hood.

a bubble column system; (2) to determine the relationship between TOC removal and ozone consumption; (3) to determine the level of toxicity reduction by ozonation; and (4) to propose an empirical formula to express the change of color, TOC, and sulfate. The results of this study could provide base-line information to both the academic community and practicing engineers.

\section{Material and Methods}

\section{Materials}

The commercialized reactive dye, RB5, $\mathrm{C}_{26} \mathrm{H}_{21} \mathrm{~N}_{5} \mathrm{Na}_{4} \mathrm{O}_{19} \mathrm{~S}_{6}$, was provided by a local manufacturer (Yi-Hwa, Taiwan) with $55 \%$ of purity, and it was used without further purification. The rest (45\%) of the commercial RB5 is assumed to contain chemicals, such as salts and surfactants; the exact composition formulation is protected by the manufacturer. The molecular weight (MW) and maximum absorption peak $\left(A_{\max }\right)$ for RB5 are $992 \mathrm{~g} / \mathrm{mol}$ and 597 $\mathrm{nm}$, respectively. The initial TOC and $\mathrm{pH}$ of RB5 $(75 \mathrm{mg} / \mathrm{L})$ in solution were $16 \pm 1 \mathrm{mg} / \mathrm{L}$ and $5.5 \pm 0.2$, respectively.

\section{Instrumentation}

Fig. 1 is a schematic diagram of the ozone contacting bubble column. The polyvinyl chloride column was $3.0 \mathrm{~m}$ high and had an inner diameter of $14.2 \mathrm{~cm}$, with an effective volume $\left(V_{L}\right)$ of $45 \mathrm{~L}$. It was operated in the countercurrent mode with watercontaining RB5 flowing downward and ozone-containing gas flowing upward continuously. Ozone-containing gas was generated with pure oxygen by an ozone generator (SG-01A, Sumi- tomo, Japan) and introduced into the column so that the mixed gas flowed through a ceramic diffuser located $10 \mathrm{~cm}$ from the bottom of the contactor. The liquid-storage tank was equipped with a thermostat to maintain a constant solution temperature of $30^{\circ} \mathrm{C}$ in all experiments. A solution with a height of about $2.6 \mathrm{~m}$ (L) was held in the column, and sample taps were installed at heights of $2.5,1.9,1.0$, and $0.4 \mathrm{~m}$ from the bottom of the contactor for sample collecting.

The dissolved ozone concentration $\left(\mathrm{O}_{3, \text { diss }}\right)$ was monitored by an ozone monitor (model 3600, Orbisphere Laboratory, Neuchàtel, Switzerland) that was equipped with a membrane-containing cathode sensor to analyze the dissolved ozone concentration and was calibrated by the indigo method. The ozone concentration in off-gas $\left(\mathrm{O}_{3, \text { off }}\right)$ was monitored by an ozone analyzer (Dasibi model 1008-HC, Calif.) and calibrated by $2 \% \mathrm{KI}$ solution. Absorbance of $A_{597 \mathrm{~nm}}$ and $254 \mathrm{~nm}\left(\mathrm{UV}_{254}\right)$ was performed by an ultraviolet (UV)-visible detector (model Cintra 20, GBC Scientific Equipment, Victoria, Australia). Visible wavelength absorbance was examined using wavelength scanning from 400 to $700 \mathrm{~nm}$ and integrating the area, expressed as integrated absorbance unit (IAU), under the absorbance curve. The IAU is proportional to the sample color mentioned in a previous study ( $\mathrm{Wu}$ and Wang 2001). A TOC analyzer (Model 1010, O.I Corporate) was employed to analyze the TOC concentration; an ion analyzer (Capillary Ion Analyzer, Waters) was used for the analysis of sulfate $\left(C_{\mathrm{SO}_{4}^{2-}}\right)$ and nitrate $\left(C_{\mathrm{NO}_{3}^{-}}\right)$generation.

\section{Experimental Procedures}

Before the ozonation experiments were started, the ozonecontaining gas was bypassed to the ozone analyzer to assure its stability and to determine the inlet ozone concentration. The ozone-enriched gas was directed into the column with a fixed ozone production of $(60 \mathrm{~g} / \mathrm{h})$. For the set of fixed liquid flow rate experiments, the gas flow rates $\left(G_{G}\right)$ were set as $0.9,2.1,2.7$, and $3.4 \mathrm{~L} / \mathrm{min}$, while the fixed liquid flow rate was $2.4 \mathrm{~L} / \mathrm{min}$. For the set of fixed gas flow rate experiments, liquid flow rates $\left(G_{L}\right)$ used in this study were $2.0,2.4,4.0$, and $6 \mathrm{~L} / \mathrm{min}$, the ozoneenriched gas flow rate was set as $2.1 \mathrm{~L} / \mathrm{min}$. The effluent liquid and samples at different heights were drawn at desired intervals to analyze the variations in $\mathrm{pH}, A_{597 \mathrm{~nm}}$, color, COD, TOC, nitrate, and sulfate in the course of the experiments. In addition, the ozone concentration and amount of the effluent and off gas were also measured. The samples for 5-day biological oxygen demand $\left(\mathrm{BOD}_{5}\right)$ tests were drawn to evaluate the enhancement of biodegradation by ozonation. The experimental conditions are listed in Table 1.

\section{Toxicological Bioassay by Microtox}

Microtox toxicological bioassay was used to measure the toxicity of the ozonated RB5 solution in this study. The decrease in respiration and subsequent light output of a luminescent bacterium Vibrio fischeri was measured to determine the level of toxic response. The EC50 of the Microtox analysis is defined as the sample concentration that reduces the reagent light output by $50 \%$ (Hu et al. 2003); it is used as an indicator to evaluate the level of toxicity in this study. The effect measured by the Microtox toxicological bioassay, light loss, is related to the rate of biological activity and is measured at $15 \mathrm{~min}$ of sample exposure time in this study. 
Table 1. Experimental Setup and Monitored Parameters at $\tau=2.5$

\begin{tabular}{lcccc}
\hline $\begin{array}{l}G_{G} \\
(1 / \min )\end{array}$ & $\begin{array}{c}G_{L} \\
(1 / \mathrm{min})\end{array}$ & Decolorization $^{\mathrm{a}, \mathrm{b}}$ & $\eta_{\text {TOC }}^{\mathrm{a}, \mathrm{c}}$ & {$\left[\mathrm{O}_{3}\right]_{\text {diss }}(\mathrm{mg} / \mathrm{L})^{\mathrm{a}}$} \\
\hline 2.1 & 2.0 & 0.98 & 0.87 & 0.88 \\
2.1 & 2.4 & 0.98 & 0.83 & 0.22 \\
2.1 & 4.0 & 0.96 & 0.73 & 0 \\
2.4 & 6.0 & 0.70 & 0.66 & 0 \\
0.9 & 2.4 & 0.50 & 0.79 & 0 \\
2.7 & 2.4 & 1.00 & 0.86 & 0.56 \\
3.3 & 2.4 & 1.00 & 0.90 & 0.9 \\
\hline
\end{tabular}

Note: $\mathrm{IAU}=$ integrated absorbance unit; and $\mathrm{TOC}=$ total organic carbon.

${ }^{\mathrm{a}}$ Measured at the exit.

${ }^{\mathrm{b}}$ Decolorization $=1-\mathrm{IAU} / \mathrm{IAU}_{0}$.

${ }^{\mathrm{c}} \eta_{\mathrm{TOC}}=1-\mathrm{TOC} \mathrm{TOC}_{0}$.

\section{Results and Discussion}

\section{Oxonation of RB5 in Bubble Column Reactor}

The ozonation profile of RB5 in $\mathrm{pH}, A_{597 \mathrm{~nm}}$, color, and TOC operated at the condition of $G_{L}=2.4 \mathrm{~L} / \mathrm{min}$ and $G_{G}=2.1 \mathrm{~L} / \mathrm{min}$ are shown in Fig. 2. As ozone was conducted into BCR, the $\mathrm{pH}$ decreased rapidly from 5.5 to 4.0 within 0.5 dimensionless ozonation time $(\tau, \tau=$ ozonation time $/ 60 \mathrm{~min})$ due to the formation of organic and inorganic acids; as the system approached a steady state, the $\mathrm{pH}$ reached a constant $(3.8 \pm 0.1)$. The unreacted RB5 existed in the effluent was nearly undetectable as $\tau>0.5$, suggesting that the RB5 removal efficiency approached $100 \%$ further implies that $\mathrm{RB} 5$ and $\mathrm{O}_{3}$ have a fast reaction. Due to the low bonding energy $(66 \mathrm{kcal} / \mathrm{mol})$, azo bonds $(\mathrm{N}=\mathrm{N})$ may be the first to be attacked by ozone, which causes a color change. Also, under acidic conditions, ozone dissolved into liquid phase and then reacted with RB5 molecules, whereas the direct reaction was dominant. The abatement of color changed from 153 to 1.6 IAU within $\tau=1$, suggesting that most chromophores in the liquid phase were destroyed by $\mathrm{O}_{3}$, and its reduction was similar to RB5 removal. The TOC reduction occurred simultaneously with decolorization, decreasing from $16 \mathrm{mg} / \mathrm{L}$ to $5 \mathrm{mg} / \mathrm{L}$ within $\tau=1$, and reached a steady constant $(3 \mathrm{mg} / \mathrm{L})$. Clearly, TOC could not be totally removed by ozone in this study because of persistent byproducts formed (Chiang et al. 1999).

It is noted that the $\mathrm{O}_{3 \text {,diss }}$ profile is concerned with the level of decolorization, and the profile is observed after the completion of decolorization, as shown in Fig. 3. The results prove that: (1) a rapid reaction occurs between $\mathrm{RB} 5$ molecules and $\mathrm{O}_{3 \text {,diss, }}$, and (2) the residual dissolved ozone can be found only after the completion of decolorization. The appearance of dissolved ozone in the effluent indicated that the dissolved ozone utilization rate slowed down and the slower TOC reduction gradually dominated. Sulfate and nitrate were found after the treatment of RB5 by ozone and were consistent with the TOC reduction; $C_{\mathrm{SO}_{4}^{2-}}$ and $C_{\mathrm{NO}_{3}^{-}}$reached 25 and $1.3 \mathrm{mg} / \mathrm{L}$, respectively, after $\tau=2$. Referring to the chemical structure of RB5, one RB5 molecule contains six sulfate groups and two azo bonds. As ozonation proceeded, the amount of sulfate released was about 20 times that of nitrate formation. Analysis of the off gas indicated the presence of gaseous nitrogen compounds (such as $\mathrm{NO}$ and $\mathrm{NO}_{2}$ ), which might explain the unbalancing of nitrogen mass during the experiment. Further, nitrate formation required the breakdown of the aromatic ring-a slower reaction compared to cleaving sulfate from an aromatic ring, suggesting that some nitrogen was not released from persistent
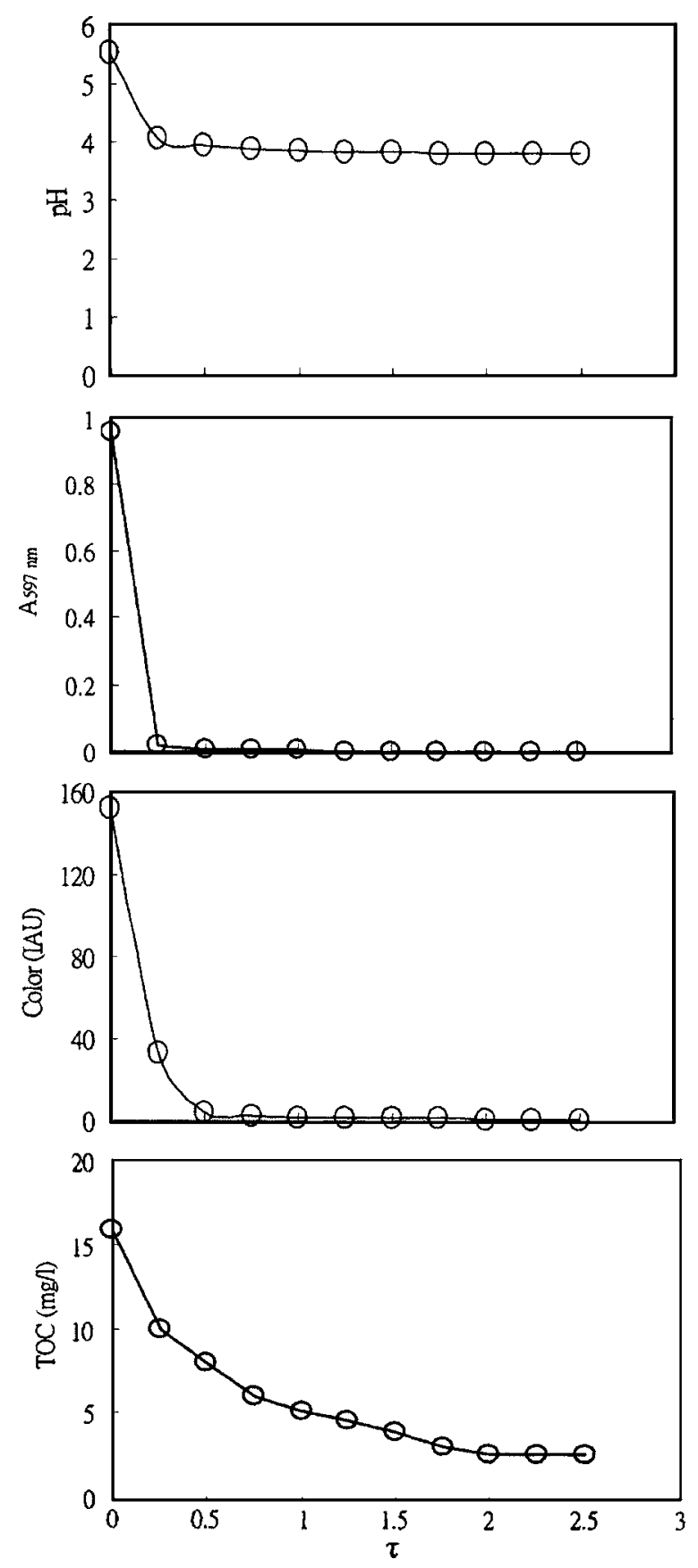

Fig. 2. RB5 ozonation profiles of $\mathrm{pH}, A_{597 \mathrm{~nm}}$, color, and total organic carbon under the conditions of $[\mathrm{RB} 5]=75 \mathrm{mg} / \mathrm{L}$, $G_{L}=2.4 \mathrm{~L} / \mathrm{min}, G_{G}=2.1 \mathrm{~L} / \mathrm{min}$, and $30^{\circ} \mathrm{C}$

byproducts. A similar observation was reported that the release of the sulfate group was faster than TOC removal and nitrate formation as oxidation of 2-merceaptothiazoline by ozone (Chen et al. 2004).

\section{Effect of Flow Patterns on RB5 Ozonation}

\section{Fixed Liquid Flow Rate}

The ozonation profile of decolorization, TOC removal efficiency $\left(\eta_{\mathrm{TOC}}, \eta_{\mathrm{TOC}}=1-\mathrm{TOC}_{i} / \mathrm{TOC}_{0}\right)$, UV removal efficiency $\left(\eta_{\mathrm{UV}}, \eta_{\mathrm{UV}}=1-\mathrm{UV} / \mathrm{UV}_{0}\right)$, and $C_{\mathrm{SO}_{4}^{2-}}$ were monitored at the exit of the BCR under a fixed liquid flow rate $\left(G_{L}=2.4 \mathrm{~L} / \mathrm{min}\right)$ while 

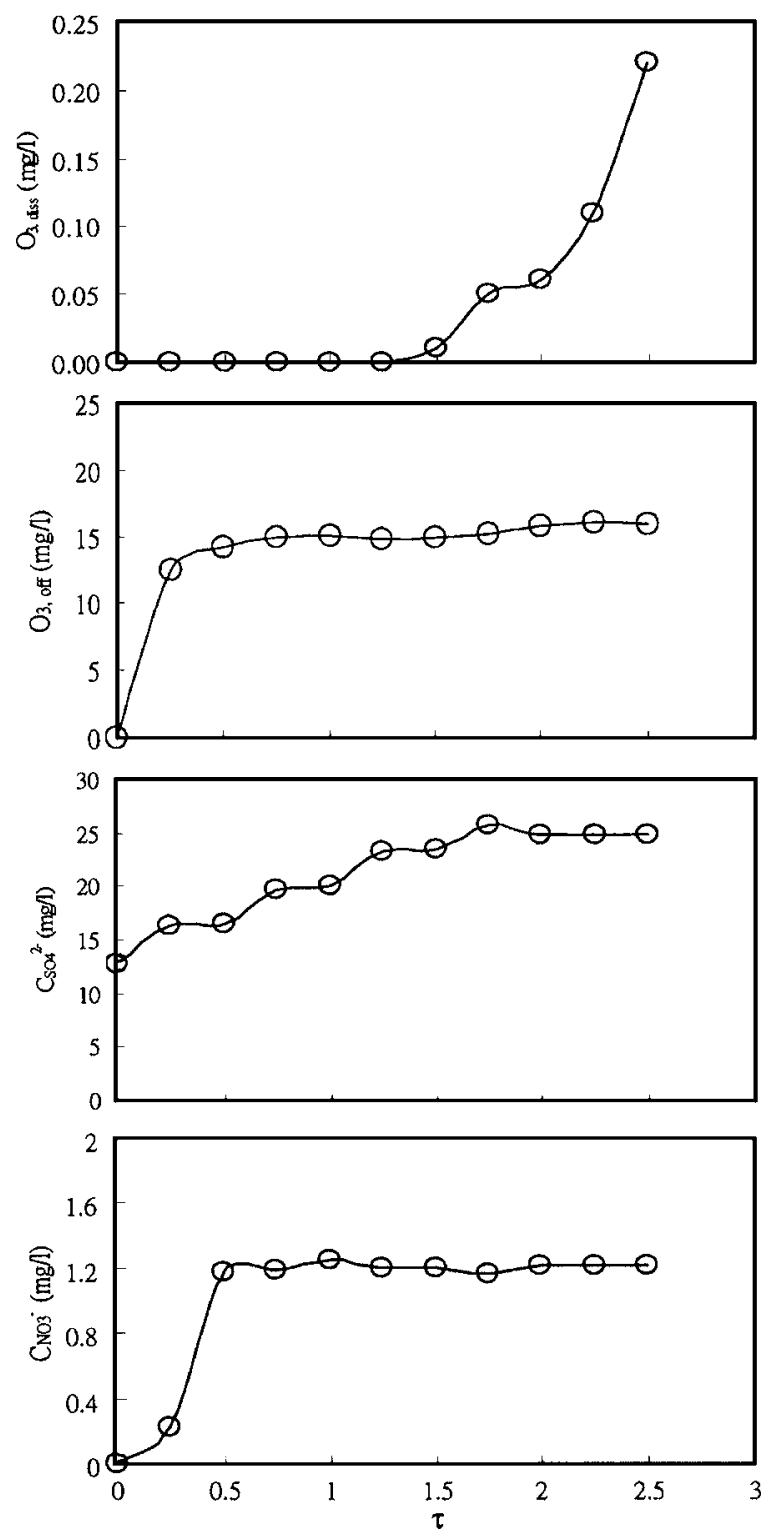

Fig. 3. RB5 ozonation profiles of ozone concentration in liquid and off-gas, sulfate, and nitrate under the conditions of [RB5] $=75 \mathrm{mg} / \mathrm{L}$, $G_{L}=2.4 \mathrm{~L} / \mathrm{min}, G_{G}=2.1 \mathrm{~L} / \mathrm{min}$, and $30^{\circ} \mathrm{C}$

changing $G_{G}$ from 0.9 to $3.4 \mathrm{~L} / \mathrm{min}$, as shown in Fig. 4 . For the variation in decolorization [Fig. 4(a)], it was clear that the smaller $G_{G}(0.9 \mathrm{~L} / \mathrm{min})$ would result in less decolorization than a high $G_{G}$, and the degree of reduction was not proportional to the increase in $G_{G}$ The results indicated that, as $G_{G}>2.1 \mathrm{~L} / \mathrm{min}$, the $G_{G}$ was not a predominant factor for decolorization because the ozone supply was more than sufficient for decolorization need; this implies that $G_{G}$ could be a primary factor in controlling decolorization as $G_{L} / G_{G}>1.14$. It suggests that the $\mathrm{O}_{3 \text {,diss }}$ was not enough to break all the existing azo bonds in the solution under the conditions of $G_{G}=0.9 \mathrm{~L} / \mathrm{min}$, the corresponding applied ozone dosage which was $1.2 \mathrm{mg} / \mathrm{L} / \mathrm{min}$. The $\eta_{\text {TOC }}$ and $\eta_{\text {UV }}$ results, as shown in Figs. 4(b and c), showed a similar increasing trend, with the extent increasing as $G_{G}$ increased, but a smaller extent for $G_{G}=0.9 \mathrm{~L} / \mathrm{min}$. The $\eta_{\text {TOC }}$ was affected by $G_{G}$, which could be viewed as an applied ozone dose in this study. As $G_{G}$ increased, the applied ozone dose increased. The higher the $G_{G}$, the more TOC could be removed, in line with the pseudo-first- order kinetic model; the amount of $\eta_{\text {TOC }}$ could improve to 0.85 , and the difference between four $G_{G}$ s was only $12 \%$.

The $\eta_{U V}$ variation may represent the level of unsaturated bonds in the effluent, which may serve as an important factor to evaluate the removal of RB5 and its derivatives by ozone. For the $\eta_{\text {UV }}$ results shown in Fig. 4(c), because of incomplete decolorization at $G_{G}=0.9 \mathrm{~L} / \mathrm{min}$, the amount of $\eta_{\mathrm{UV}}$ reached only 0.6 , significantly lower than that in other $G_{G}$ s. It proved that a certain amount of organics was not ozonated and discharged with the effluent. Also, it is noted that there was little difference among the $\eta_{U V}$ for $G_{G}=2.1,2.7$, and $3.4 \mathrm{~L} / \mathrm{min}$, consistent with the explanation of decolorization. $C_{\mathrm{SO}_{4}^{2-}}$ was consistent with diminishing TOC as mentioned before, and $C_{\mathrm{SO}_{4}^{2-}}$ increased as $G_{G}$ increased, ranging from $0.1 \mathrm{mM}\left(G_{G}=0.9 \mathrm{~L} / \mathrm{min}\right)$ to $0.15 \mathrm{mM}$ $\left(G_{G}=3.4 \mathrm{~L} / \mathrm{min}\right)$. An exponential correlation was observed strongly between $C_{\mathrm{SO}_{4}^{2-}}$ and $G_{G}$, as shown in Fig. 4(d).

\section{Fixed Gas Flow Rate}

Similar approaches were followed in the fixed liquid flow experiments, with fixed $G_{G}=2.1 \mathrm{~L} / \mathrm{min}$ and increasing $G_{L}$ from 2 to $6 \mathrm{~L} / \mathrm{min}$ to observe the variations in decolorization, $\eta_{\mathrm{UV}}, \eta_{\mathrm{TOC}}$, and $C_{\mathrm{SO}_{4}^{2-}}$ (Fig. 5). As shown in Fig. 5(a), the decolorization for four $G_{L} \mathrm{~s}$ exhibited slight differences, although all were above 0.9; the only exception was under the condition of $G_{L}=6 \mathrm{~L} / \mathrm{min}$, where the decolorization amounted to only 0.7 . The difference between the decolorization under the conditions of $G_{L}=2$ and $6 \mathrm{~L} / \mathrm{min}$ was about 0.28 , indicating that the ozone dose was not enough to consume all RB5 under the $G_{L}=6 \mathrm{~L} / \mathrm{min}$ condition; for the other three $G_{L}$ s, the differences between them were not significant. For $\eta_{\text {TOC }}$ measurements, as shown in Fig. 5(b), it was found that $\eta_{\text {TOC }}$ reached steady states after $\tau=1.5$, except for the case of $G_{L}=2.4 \mathrm{~L} / \mathrm{min}$. The differences among $G_{L}=2,4$, and $6 \mathrm{~L} / \mathrm{min}\left(\eta_{\mathrm{TOC}}=0.86,0.74\right.$, and 0.33 respectively $)$ were remarkable, indicating that $\eta_{\text {TOC }}$ decreased as $G_{L}$ increased. This meant that the TOC reduction correlated with the ozone dose, the processes of decolorization, and the TOC reduction (at $G_{L}$ $=6 \mathrm{~L} / \mathrm{min}$ ) competed for ozonation. For the cases of $G_{L}=2$ and $2.4 \mathrm{~L} / \mathrm{min}$, the average $\eta_{\text {TOC }}$ was more than 0.8 in both instances, suggesting that ozone mass transfer efficiencies in the BCR were better than in a semibatch reactor as Chen et al. (2003) reported.

Fig. 5(c) illustrates the $\eta_{\mathrm{UV}}$ variation that suggests correlation between $\eta_{\mathrm{UV}}$ and $G_{L}$ under fixed $G_{G}$ conditions. As $G_{L}$ increased from 2 to $6 \mathrm{~L} / \mathrm{min}$, $\eta_{\mathrm{UV}}$ decreased from 0.78 to 0.28 under fixed $G_{G}$, indicating that the ozone supply was a significant controlling factor on $\eta_{U V}$. Also, from the dissolved ozone profile, compiled by monitoring the $\mathrm{BCR}$, it is obvious that no dissolved ozone was measured under a high $G_{L}$ condition. It is clear that dissolved ozone was consumed right after its dissolution, suggesting that a quick interaction occurred. Also, it indicated that the extent of $C_{\mathrm{SO}_{4}^{2-}}$ did not significantly reduce as $G_{L}$ increased.

The results of the comparison of $\eta_{\mathrm{TOC}}$ and $C_{\mathrm{SO}_{4}^{2-}}$ under both conditions of fixed $G_{L}$ and $G_{G}$ are shown in Fig 6. It is observed that the effect of $G_{L} / G_{G}$ on $\eta_{\text {TOC }}$ was more significant than that on $C_{\mathrm{SO}_{4}^{2-}}$; both appeared as an exponential decay trend with $R^{2}$ of 0.89 and 0.86 , respectively. The rate of $\eta_{\text {TOC }}$ decreased more rapidly than $C_{\mathrm{SO}_{4}^{2-}}$ as $G_{L} / G_{G}$ increased, and the ratio of $\eta_{\mathrm{TOC}}$ decreasing was about six times of that of $C_{\mathrm{SO}_{4}^{2-}}$. 

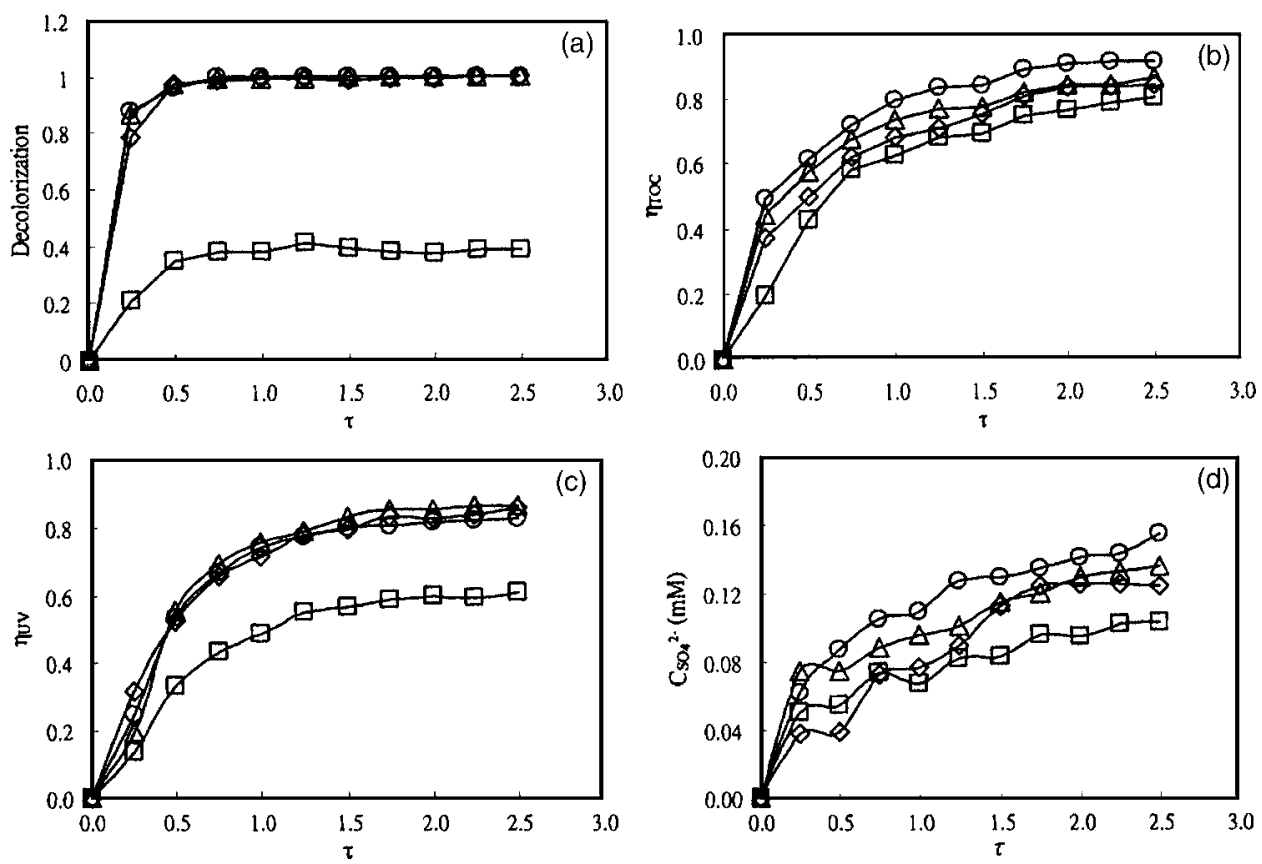

Fig. 4. Variation profiles of (a) decolorization, (b) $\eta_{\mathrm{TOC}}$, (c) $\eta_{\mathrm{UV}}$, and (d) $C_{\mathrm{SO}_{4}^{2-}}$ at the exit for four different gas flow rates under $G_{L}=2.4 \mathrm{~L} / \mathrm{min}$ conditions. Notation: $\square: G_{G}=0.9 \mathrm{~L} / \mathrm{min}, \diamond: G_{G}=2.1 \mathrm{~L} / \mathrm{min}, \triangle: G_{G}=2.7 \mathrm{~L} / \mathrm{min}$, and $\bigcirc: G_{G}=3.4 \mathrm{~L} / \mathrm{min}$.

\section{Ozone Consumption Associated with Total Organic Carbon Removal}

By measuring the ozone concentration in the off-gas and the effluent at the exit, the ozone consumption $\left(m_{\mathrm{O}_{3}}\right)$ can be calculated as follows:

$$
m_{\mathrm{O}_{3}}=\int_{0}^{t} G_{G}\left(C_{A o}-C_{A e}\right) d t
$$

where $C_{A e}=$ ozone concentration at the outlet.
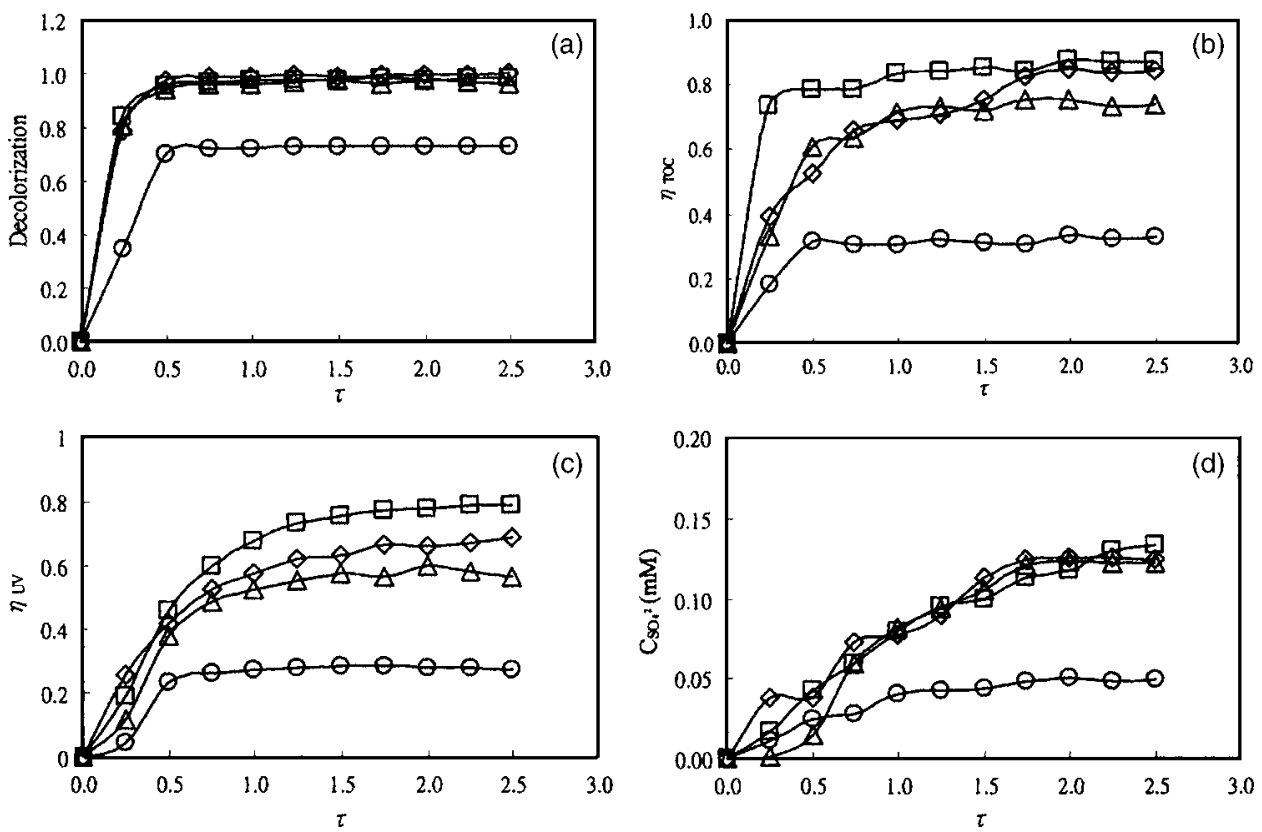

Fig. 5. Variation profiles of (a) decolorization, (b) $\eta_{\mathrm{TOC}}$, (c) $\eta_{\mathrm{UV}}$, and (d) $\mathrm{C}_{\mathrm{SO}_{4}^{2-}}$ at the exit for four different liquid flow rates under $G_{G}=2.1 \mathrm{~L} / \mathrm{min}$ conditions. Notation: $\square: G_{L}=2.0 \mathrm{~L} / \mathrm{min}, \diamond: G_{L}=2.4 \mathrm{~L} / \mathrm{min}, \triangle: G_{L}=4.0 \mathrm{~L} / \mathrm{min}, \bigcirc:$ and $G_{L}=6.0 \mathrm{~L} / \mathrm{min}$. 


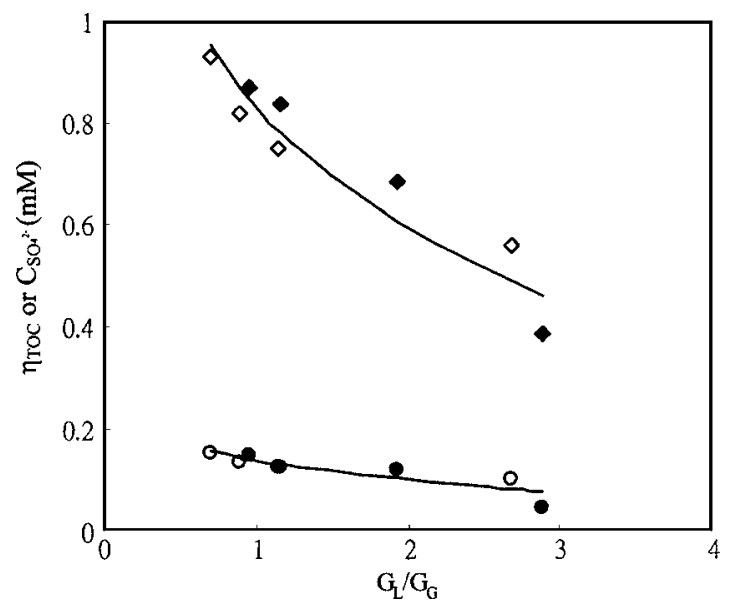

Fig. 6. Correlation of $\eta_{\mathrm{TOC}}$ and $\mathrm{C}_{\mathrm{SO}_{4}^{2-}}$ versus $G_{L} / G_{G}$ under fixed $G_{L}(2.4 \mathrm{~L} / \mathrm{min})$ and $G_{G}(2.1 \mathrm{~L} / \mathrm{min})$ conditions. Notation: fixed $G_{L}$, fixed $G_{G}: \diamond, \diamond: \eta_{\text {TOC }}, R^{2}=0.89 ; \bigcirc, \bullet: C_{\mathrm{SO}_{4}^{2-}}, R^{2}=0.76$.

tion of $\mathrm{TOC}_{i} / \mathrm{TOC}_{0}$ in relation to $m_{\mathrm{O}_{3}}$ is shown in Fig. 8. Because of the limitation of $\mathrm{O}_{3}$ supply, the TOC reduction might act as a second-order reaction rate as expressed by the following kinetic equation:

$$
d \mathrm{TOC} / d t=k[\mathrm{TOC}]\left[\mathrm{O}_{3}\right]
$$

As seen in Fig. 8, TOC $_{i} / \mathrm{TOC}_{0}$ decreased as $m_{\mathrm{O}_{3}}$ increased. As $G_{L}$ increased from 2 to $6 \mathrm{~L} / \mathrm{min}$, the levels of $\mathrm{TOC}_{i} / \mathrm{TOC}_{0}$ were higher. It is obvious that $G_{L}$ was the controlling factor in TOC reduction under fixed $G_{G}$ conditions, since $\mathrm{TOC}_{i} / \mathrm{TOC}_{0}$ escalated as $G_{L}$ increased. As the amount of $m_{\mathrm{O}_{3}}$ approached $4 \mathrm{~g}$, the difference of $\mathrm{TOC}_{i} / \mathrm{TOC}_{0}$ between $G_{L}=2$ and $6 \mathrm{~L} / \mathrm{min}$ reached $23 \%$, indicating that the chemical reaction between RB5 and the amount of dissolved $\mathrm{O}_{3}$ controlled the TOC reduction rate.

Figs. 9(a and b) show the effect of ozonation on the $\mathrm{BOD}_{5} / \mathrm{COD}$ enhancement of two flow patterns; both figures illustrate the positive correlation between $\mathrm{BOD}_{5} / \mathrm{COD}$ and $m_{\mathrm{O}_{3}}$. As $m_{\mathrm{O}_{3}}$ increased, the $\mathrm{BOD}_{5} / \mathrm{COD}$ increased substantially from $<0.1$ to 1.0 and 0.5 as $m_{\mathrm{O}_{3}}=4.6 \mathrm{~g}$ for fixed $G_{G}$ and $G_{L}$ conditions, and the trend of $\mathrm{BOD}_{5} / \mathrm{COD}$ appeared as a function of $m_{\mathrm{O}_{3}}$. The phenomenon could be attributed to the reaction between ozone and RB5 molecules, which opened the long-chain high MW,

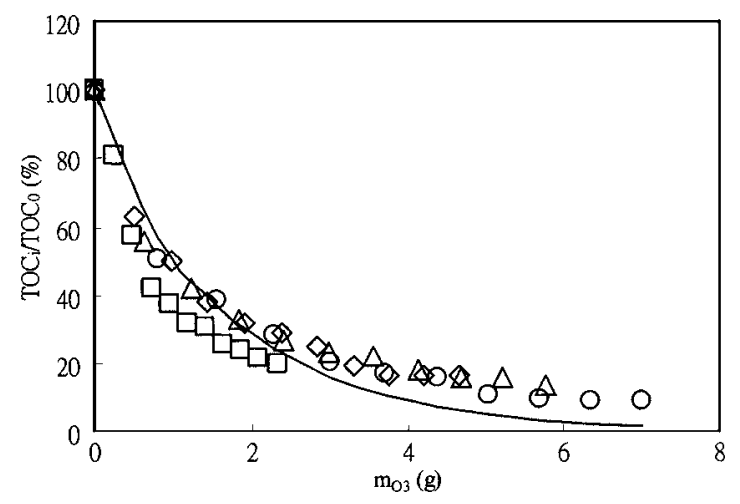

Fig. 7. $\mathrm{O}_{3}$ consumption $\left(m_{\mathrm{O}_{3}}\right)$ versus total organic carbon $\left(\mathrm{TOC}_{i} / \mathrm{TOC}_{0}\right)$ variations at fixed liquid flow $\left(G_{L}=2.4 \mathrm{~L} / \mathrm{min}\right)$ condition, $R^{2}=0.90$. Notation: $\square: G_{G}=0.9 \mathrm{~L} / \mathrm{min}, \diamond: G_{G}=2.1 \mathrm{l} / \mathrm{min}$, $\triangle: G_{G}=2.7 \mathrm{~L} / \mathrm{min}$, and $\bigcirc: G_{G}=3.4 \mathrm{~L} / \mathrm{min}$.

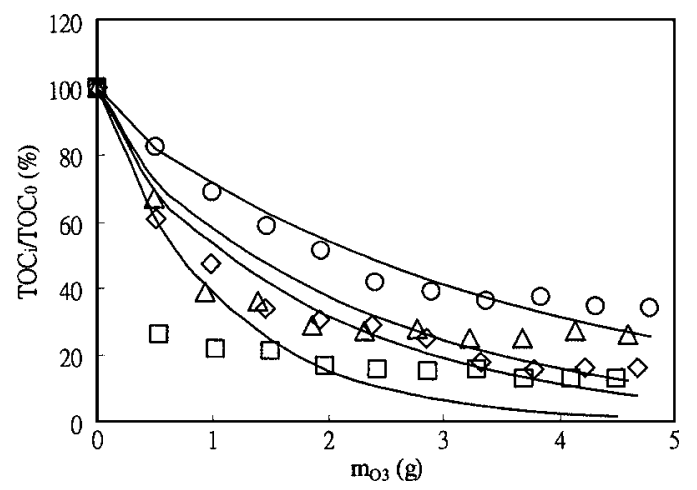

Fig. 8. The $\mathrm{O}_{3}$ consumption $\left(m_{\mathrm{O}_{3}}\right)$ versus total organic carbon $\left(\mathrm{TOC}_{\mathrm{i}} / \mathrm{TOC}_{0}\right)$ variations at fixed gas flow rate $\left(G_{G}=2.1 \mathrm{~L} / \mathrm{min}\right)$ conditions. Notation: $\square: G_{L}=2.0 \mathrm{l} / \mathrm{min}, \diamond: G_{L}=2.4 \mathrm{~L} / \mathrm{min}, \triangle$ : $G_{L}=4.0 \mathrm{l} / \mathrm{min}$, and $\bigcirc: G_{L}=6.0 \mathrm{~L} / \mathrm{min}$.

and/or the reaction of RB5, which is not biodegradable, with the simple biodegradable organic compounds present in the water. Because of low $\mathrm{BOD}_{5} / \mathrm{COD}$ in initial conditions, the effect of ozonation on increasing the $\mathrm{BOD}_{5} / \mathrm{COD}$ of the final ozonated effluent was expected to be high, indicating that the biodegradability was enhanced by ozone treatment.
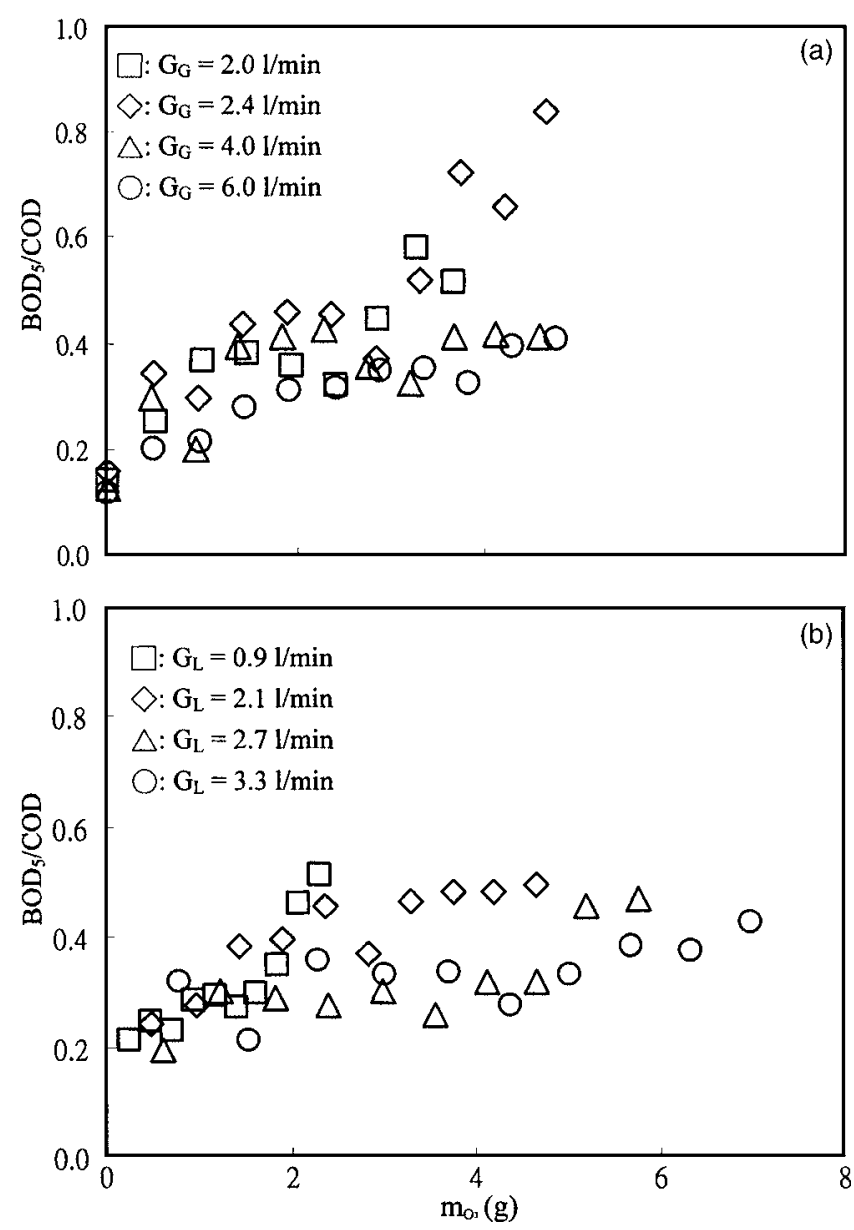

Fig. 9. The effect of $\mathrm{O}_{3}$ consumption $\left(m_{\mathrm{O}_{3}}\right)$ on $\mathrm{BOD}_{5} / \mathrm{COD}$ enhancing. (a) Fixed gas flow rate $\left(G_{G}=2.1 \mathrm{~L} / \mathrm{min}\right)$; and (b) fixed liquid flow rate $\left(G_{L}=2.4 \mathrm{~L} / \mathrm{min}\right)$. 
Table 2. Parameter Estimates for Eq. (3)

\begin{tabular}{llccc}
\hline & $a$ & $b$ & $c$ & $R^{2}$ \\
\hline Color $_{i} /$ color $_{0}$ & 0.0127 & -2.78 & -0.606 & $0.83(40)$ \\
$\mathrm{TOC}_{i} / \mathrm{TOC}_{0}$ & 0.149 & -0.686 & -0.220 & $0.86(40)$ \\
$Y_{\mathrm{SO}_{4}^{2-}}$ & 0.198 & 0.123 & 0.671 & $0.80(40)$
\end{tabular}

Note: The number in the parenthesis indicates the samples size. $\mathrm{TOC}=$ total organic carbon

\section{Column Height Effect on Reduction of Color and Total Organic Carbon, and Sulfate Formation}

Since the BCR used in this study had a countercurrent flow pattern, with liquid flowing downward, and ozone-enriched gas flowing upward, the ozone contacting time was affected by column height $(H)$ under both experimental designs. Some investigators have shown that color and TOC reduction are affected by ozonation time and ozone dosage (Perkowski et al. 1996; Konsowa, 2003) as well as column height (Chen et al. 2003). Thus, the variation in color change, TOC reduction, and sulfate yield $\left[Y_{\mathrm{SO}_{4}^{2-}}\right.$, defined as $Y_{\mathrm{SO}_{4}^{2-}}=\left(C_{\mathrm{SO}_{4}^{2-}, i}-C_{\mathrm{SO}_{4}^{2-}, 0}\right) /$ $\left.\left(C_{\mathrm{SO}_{4}^{2-} \text {,total }}-C_{\mathrm{SO}_{4}^{2-}, 0}\right)\right]$ in the $\mathrm{BCR}$ during the ozonation process could be predicted and expressed as color ${ }_{i} /$ color $_{0}$ or $\mathrm{TOC}_{i} / \mathrm{TOC}_{0}$, or $Y_{\mathrm{SO}_{4}^{2-}}$ could be expressed as follows:

$$
Y=a \times\left(\frac{G_{L}}{G_{G}}\right)^{b} \times\left(1-\frac{H}{2.6}\right)^{c}
$$

where $Y=$ color $_{i} /$ color $_{0} ; \mathrm{TOC}_{i} / \mathrm{TOC}_{0}, \quad$ or $Y_{\mathrm{SO}_{4}^{2-} ; a, \quad b,}$ and $c=$ constants; and $H=$ depth of water column.

The results of $a, b$, and $c$ are listed in Table 2. The profile predictions for color ${ }_{i} /$ color $_{0}, \mathrm{TOC}_{i} / \mathrm{TOC}_{0}$, or $Y_{\mathrm{SO}_{4}^{2-}}$ of two flow patterns are shown in Figs. 10 and 11, respectively. In Fig. 10, both color and TOC decreased as the gas flow rate increased while $Y_{\mathrm{SO}_{4}^{2-}}$ increased, indicating that the reduction profiles were controlled by $G_{G}$ ozone dose. Furthermore, the ozone contacting time (i.e., column height) affected the extent of color $_{i} /$ color $_{0}$, $\mathrm{TOC}_{i} / \mathrm{TOC}_{0}$, and $Y_{\mathrm{SO}_{4}^{2-}}$; it was observed that the reducing profiles minimized concurrently with increasing column height. The results prove that the ozone contacting time is related to ozone consumption in the BCR system; a taller BCR would result in higher ozone consumption. The results also suggest that column height could significantly affect the decolorization and mineralization performance in the BCR. For the effects of fixed gas flow rates, it is observed that the reducing extents of color $_{i} /$ color $_{0}$ and $\mathrm{TOC}_{i} / \mathrm{TOC}_{0}$ are the opposite of those under fixed gas flow rate conditions, indicating that the ozone supply is a limiting factor and the effect of column height may be an important factor in controlling the profiles of color $/$ color $_{0}$ and $\mathrm{TOC}_{i} / \mathrm{TOC}_{0}$ reduction, as well as the increment of $Y_{\mathrm{SO}_{4}^{2-}}$.

\section{Toxicological Bioassay by Microtox}

The toxicity reduction of RB5 solution treated by ozone was determined by comparing the toxicity before ozonation. As the toxicity was reduced to a nontoxic level, the EC50 was assumed to be $100 \%$. The toxicity reduction could be defined as follows (Jones and Huang 2003):

$$
\text { Toxicity reduction }=\frac{\text { EC50 }(\text { after })-\text { EC50 }(\text { before })}{100 \%-\text { EC50 }(\text { before })}
$$

where EC50(after) $=\mathrm{EC} 50$ value of toxicity after ozonation; and $\mathrm{EC} 50$ (before) $=$ the EC50 value of RB5 before ozonation. Fig. 12
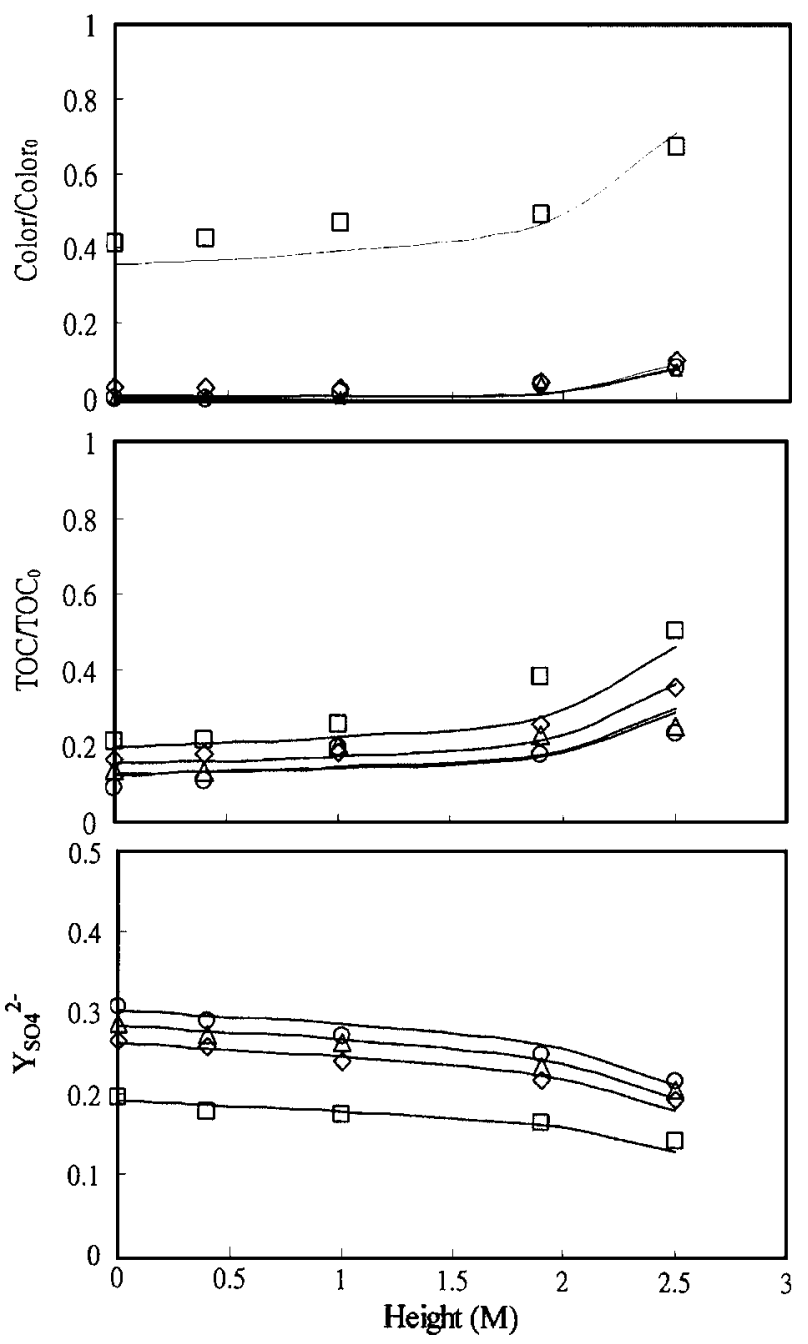

Fig. 10. The prediction profile for color $_{i} /$ color $_{0}$, total organic carbon $\left(\mathrm{TOC}_{i} / \mathrm{TOC}_{0}\right)$, or $Y_{\mathrm{SO}_{4}^{2-}}$ at $\tau=2.5$ under fixed liquid flow $\left(G_{L}=2.4 \mathrm{~L} / \mathrm{min}\right)$ condition. Notation: $\square: G_{G}=0.9 \mathrm{~L} / \mathrm{min}, \diamond$ : $G_{G}=2.1 \mathrm{~L} / \mathrm{min}, \triangle: G_{G}=2.7 \mathrm{~L} / \mathrm{min}$, and $\bigcirc: G_{G}=3.4 \mathrm{~L} / \mathrm{min}$.

depicts the toxicity reduction by the $G_{L} / G_{G}$ based on Eq. (4). The largest toxicity reduction occurs at $G_{L} / G_{G}<0.9$; it decreases as $G_{L} / G_{G}$ increases, and the trend does not appear to be linear. Also, as seen in Fig. 12, the toxicity reduction approaches 0.33 as the $G_{L} / G_{G}$ values $>2.0$. It is clear that the performance of toxicity reduction is not significant under higher $G_{L}$ conditions, indicating that ozone dosage could be a controlling factor of toxicity reduction. The results suggest that $G_{L} / G_{G}<1.0$ may have achieved total toxicity reduction in this study. The effect of ozone consumption on the toxicity reduction and $C_{\mathrm{SO}_{4}^{2-}}$ at $\tau=2.5$ are illustrated in Fig. 13. From the figure, it showed that the $C_{\mathrm{SO}_{4}^{2-}}$ was within range of 0.1 to $0.17 \mathrm{mM}$, whereas the amount of $m_{\mathrm{O}_{3}}$ increased from 4.5 to $7.0 \mathrm{~g}$. Under the same range of $m_{\mathrm{O}_{3}}$, the toxicity reduction increases from 0.29 to 1.0 and the value of toxicity reduction increases dramatically from 0.3 to 1.0 at $m_{\mathrm{O}_{3}}=4.7 \mathrm{~g}$, it implies the optimal $m_{\mathrm{O}_{3}}$ value for total toxicity reduction in this study.

\section{Conclusion}

RB5 is a long-chain diazo dye with high MW that is widely applied in industry. Traditional parameters, such as $\mathrm{pH}, A_{597 \mathrm{~nm}}$, 

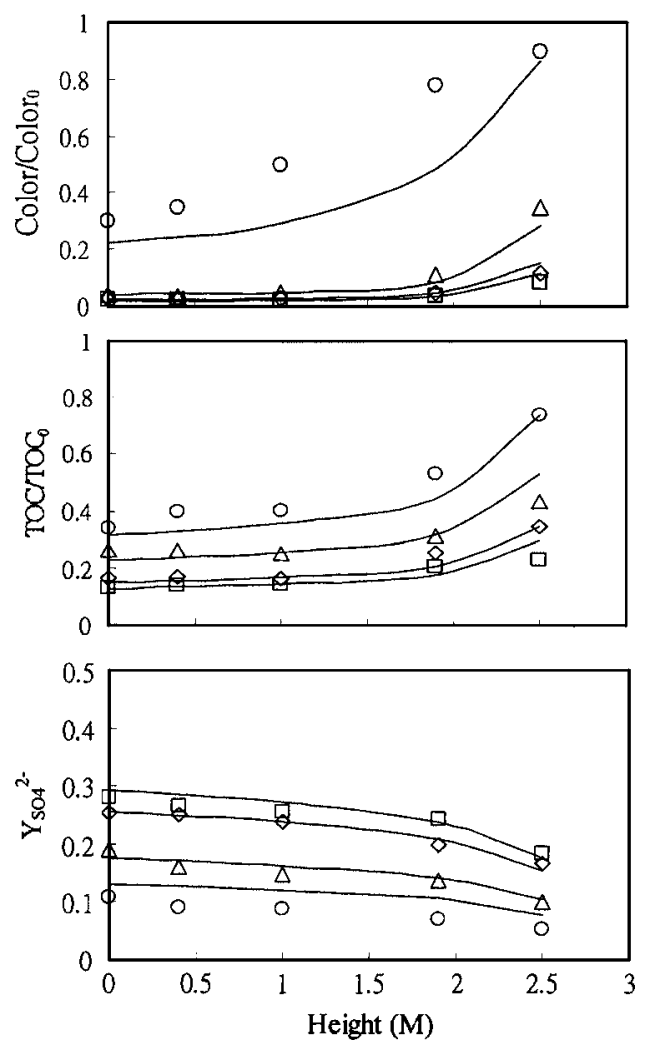

Fig. 11. Prediction profile for color $_{i} /$ color $_{0}$, total organic carbon $\left(\mathrm{TOC}_{i} / \mathrm{TOC}_{0}\right)$ or $Y_{\mathrm{SO}_{4}^{2-}}$ at $\tau=2.5$ under a fixed gas flow rate $\left(G_{G}=2.1 \mathrm{~L} / \mathrm{min}\right)$ conditions. Notation: $\square: G_{L}=2.0 \mathrm{~L} / \mathrm{min}, \diamond$ : $G_{L}=2.4 \mathrm{~L} / \mathrm{min}, \triangle: G_{L}=4.0 \mathrm{~L} / \mathrm{min}$, and $\bigcirc: \mathrm{G}_{\mathrm{L}}=6.0 \mathrm{~L} / \mathrm{min}$.

color strength, TOC, $\mathrm{O}_{3}$ concentration, $C_{\mathrm{SO}_{4}^{2-}}$, and $C_{\mathrm{NO}_{3}^{-}}$, are monitored when RB5 solution is conducted into a continuously countercurrent BCR system, and their variations may be controlled by the flow rates of liquid and/or gas. Thus, the trend may appear as a pseudo-first-order or global-second-order reaction type, depending upon the controlled flow. It is noted that the monitored parameters all achieve constants as the system ap-

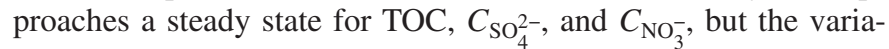
tions of $\mathrm{pH}, A_{597 \mathrm{~nm}}$, and color all reach steady constants at $\tau=1$. The work suggests that decolorization and RB5 species removal are easily achieved compared to TOC reduction.

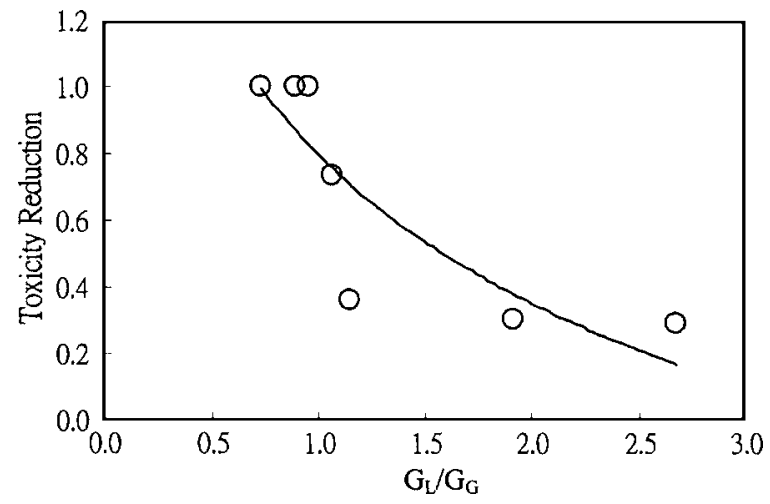

Fig. 12. Toxicity reduction of RB5 under different $G_{L} / G_{G}$ values at $\tau=2.5$

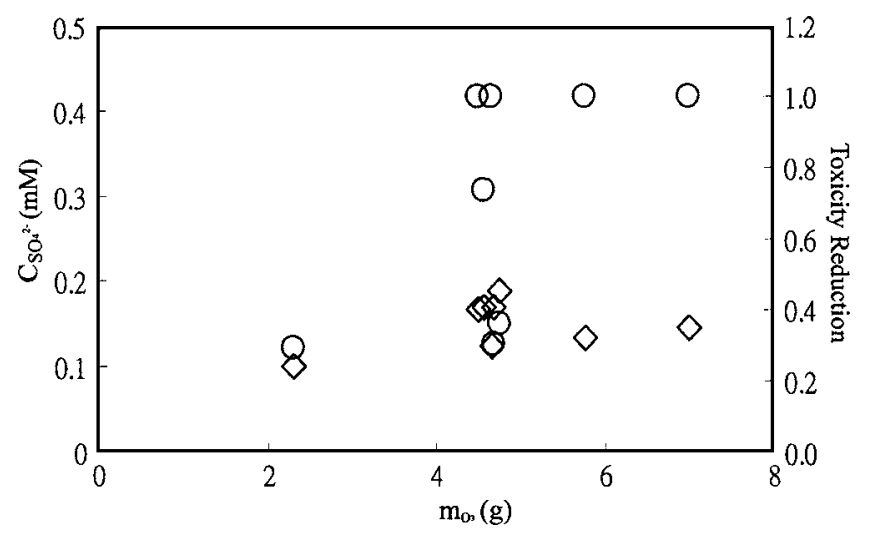

Fig. 13. Effect of ozone consumption on the toxicity reduction and $C_{\mathrm{SO}_{4}^{2-}}$ at $\tau=2.5$. Notation: $\bigcirc$ : toxicity reduction, and $\diamond: C_{\mathrm{SO}_{4}^{2-}}$.

The controlled flow may have an effect on the order of the reaction; a pseudo-first-order reaction was suggested in the fixed liquid flow rate experiments, and a second-order reaction might be suitable for the fixed gas flow rate conditions. Not only do flow patterns influence RB5 removal and the mineralization of derivatives, but column height may also have an influence on ozone consumption. It is observed that the extents of decolorization and mineralization decrease as the sampling port height increases, indicating that the column height may reflect the retention time of ozone gas and the contacting time between ozone and RB5 in the BCR system. Biodegradability is enhanced via ozone treatment by measuring the values of $\mathrm{BOD}_{5} / \mathrm{COD}$, which do not appear to be linear to the amount of ozone consumption. However, all results exhibit similar increment trends. The toxicity reduction is estimated by measuring the EC50 of effluent. The largest toxicity reduction occurs at $G_{L} / G_{G}<0.9$; it decreases as $G_{L} / G_{G}$ increasing, and the trend does not appear to be linear. As $G_{L} / G_{G}$ values $>2.0$, the toxicity reduction approaches only to 0.33 in this study. Because of the column height and flow pattern effects, an experimental regression model was proposed in this study to predict the variations of color $/$ / color $0, \mathrm{TOC}_{i} / \mathrm{TOC}_{0}$, and $Y_{\mathrm{SO}_{4}^{2-}}$ under such conditions.

\section{References}

Adams, C. D., and Gorg, S. (2002). "Effect of pH and gas-phase ozone concentration on the decolorization of common textile dyes." J. Environ. Eng., 128(3), 293-298.

Arslan, I., and Balcioglu, I. A. (2000). "Effect of common reactive dye auxiliaries on the ozonation of dyehouse effluents containing vinylsulphone and aminochlorotriazine dyes." Desalination, 130(1), 61-71.

Chen, Y. H., et al. (2004). "Decomposition of 2-mercaptothiazoline in aqueous solution by ozonation." Chemosphere, 56(2), 113-140.

Chen, Y. H., et al. (2003). "Dynamic behavior of ozonation with pollutant in a countercurrent bubble column with oxygen transfer." Water Res., 37(11), 2583-2594.

Chen, Y. H., et al. (2002). "A dynamic model of ozone disinfection in a bubble column with oxygen mass transfer." J. Chin. Inst. Chem. Eng., 33(3), 253-265.

Chiang, P. C., Ko, Y. W., Liang, C. H., and Chang, E. E. (1999). "Modeling an ozone bubble column for predicting its disinfection efficiency and control of DBP formation." Chemosphere, 39(1), 55-70.

Deckwer, W. D., and Schumpe, A. (1993). "Improved tools for bubble column reactor design and scale-up." Chem. Eng. Sci., 48(5), 889-991. 
European Union. (2003). "European Union Council Directive 2003/ 53/EC amending for the 26th time Council Directive 76/769/EEC relating to restrictions on the marketing and use of certain dangerous substances and preparations (nonylphenol, nonylphenol ethoxylate, and cement)." European Union, L178, 24-27.

Hermanowicz, S. W., Bellamy, W. D., and Fung, L. C. (1999). "Variability of ozone reaction kinetics in batch and continuous flow reactors." Water Res., 33(9), 2130-2138.

Hu, C., Yu, J. C., Hao, Z., and Wong, P. K. (2003). "Photocatalytic degradation of triazine-containing azo dyes in aqueous $\mathrm{TiO} 2$ suspensions." Appl. Catal., B, 42(1), 47-55.

Ince, N. H., and Tezcanlí, G. (2001). "Reactive dyestuff degradation by combined sonolysis and ozonation." Dyes Pigm., 49(3), 145-153.

Jones, K. D., and Huang, W.-H. (2003). "Evaluation of toxicity of the pesticides, chlorpyrifos and arsenic, in the presence of compost humic substances in aqueous systems." J. Hazard. Mater., B103(1-2), 93-105.

Konsowa, A. H. (2003). "Decolorization of wastewater containing direct dye by ozonation in a batch bubble column reactor." Desalination,
158(1-3), 233-240.

Pielesz, A., Baranowska, I., Rybak, A., and Wlochowicz. A. (2002) "Detection and determination of aromatic amines as products of reductive splitting from selected azo dyes." Ecotoxicol. Environ. Saf. 53(1), 42-47.

Perkowski, J., Kos, L., and Ledakowicz, S. (1996). "Application of ozone in textile wastewater treatment." Ozone: Sci. Eng., 18(1), 73-85.

Sevimli, M. F., and Sarikaya, H. Z. (2002). "Ozone treatment of textile effluents and dyes: Effect of applied ozone dose, $\mathrm{pH}$, and dye concentration." J. Chem. Technol. Biotechnol. 77(7), 842-850.

Wang, C., Yediler, A., Lienert, D., Wang, Z., and Kettrup, A. (2003). "Ozonation of an azo dye C.I. Remazol Black 5 and toxicological assessment of its oxidation products." Chemosphere, 52(7), $1225-1232$.

Wu, J., and Wang, T. (2001). "Ozonation of aqueous azo dye in a semibatch reactor." Water Res., 35(4), 1093-1099.

Zhou, H., Smith, D. W., and Stanley, S. J. (1994). "Modeling of dissolved ozone concentration profiles in bubble columns." J. Environ. Eng., 120(4), 821-840. 